\title{
68-Ağrı İbrahim Çeçen Üniversitesi örneğinde Türkçe-Rusça ve Rusça-Türkçe metin çevirileri dersleri
}

\section{Kamala Tahsin KARİMOVA1}

\section{Can INAL2}

\begin{abstract}
APA: Karimova, K. T.; İnal, C. (2020). Ağrı İbrahim Çeçen Üniversitesi örneğinde Türkçe-Rusça ve Rusça-Türkçe metin çevirileri dersleri. RumeliDE Dil ve Edebiyat Araștırmaları Dergisi, (Ö8), 860871. DOI: $10.29000 /$ rumelide. 822037
\end{abstract}

\section{$\ddot{\mathbf{O} z}$}

Günümüzde birçok çeviri türü bulunmaktadır: senkronize, konferanslarda ardışık, radyo ve televizyon yayınları (medya), kaset kayıtları vb. Ve bu bağlamda, modern dünyada iyi bir çevirmenin rolü her zaman ön planda olacaktır. Kültürel, ekonomik ve politik bağların gelişmesi ile bağlantılı olarak Rusça-Türkçe ve Türkçe-Rusça çeviri çalışmalarına olan ilgi gittikçe artmaktadır. Aynı zamanda, Rus dilini öğrenmek Bağımsız Devletler Topluluğu ülkelerinin temsilcileriyle iletişim kurmak için firsat vermektedir. Dilsel olmayan bir ortamda Rus Dili öğretiminde (özellikle Türkiye'de), önemli faktörler göz önünde bulundurulmalıdır. Bu, her şeyden önce, eğitim sistemi için bir zihniyet meselesidir. Öğrencilerin kültürel birikimlerinin artırılması ve ulusal eğitim sisteminin özelliklerine ilişkin bilgilerin uygulamalı olarak öğrencilere aktarılması, eğitim sürecinin iyileştirilmesine katkıda bulunacaktır. Ağrı İbrahim Çeçen Üniversitesi Fen Edebiyat Fakültesi Rus Dili ve Edebiyatı Bölümü öğretim elemanları olarak, bütün "Türkçe-Rusça” ve "Rusça-Türkçe” çeviri derslerinde, Türk öğrencilerin karşılaştıkları bazı zorlukları gözlemlemekteyiz. Zorlukların üstesinden gelmek için öncelikle nedenleri tanımlamakta fayda vardır. Aşağıda bu nedenlerden bazıları sıralanmıştır: Türk öğrencilere, Rus Dili ve Edebiyatı eğitimi verilmesi sürecinde, "TürkçeRusça” ve "Rusça-Türkçe" çeviri derslerinin öğretimi açısından irdelendiğinde, en zor alanlardan birinin dilbilgisi olduğu unutulmamalıdır. Çünkü Türkçedeki kelimelerin çoğu belirsizdir ve bu kelimeler Rus dilinde, her biri birbirinden tamamen farklı, birkaç anlama karşılık gelmektedir. Bu çalışmada, Fen-Edebiyat Fakültesi Rus Dili ve Edebiyatı Bölümü'nde fonoloji, Türkçe-Rusça ve Rusça-Türkçe çeviri, kültürlerarası iletişim, Rus-Türk Kültür diyaloğu ve diğer disiplinlerin öğretiminde yer alan özellikler vurgulanmıştır. Ağrı İbrahim Çeçen Üniversitesi örneğinde TürkçeRusça, Rusça-Türkçe çeviri dersleri, derslerde gözlemlenen zorluklar ve çözüm önerileri çalışmanın amacını oluşturmaktadır.

Anahtar kelimeler: Çeviri, Ağrı İbrahim Çeçen Üniversitesi, Kültürlerarası İletişim, Türk ve Rus dillerinin özellikleri, milli ve kültürel özellikler

Doç. Dr., Ağrı İbrahim Çeçen Üniversitesi, Fen-Edebiyat Fakültesi, Rus Dili ve Edebiyatı Bölümü (Ağrı, Türkiye), sadirzadekerimova@mail.ru, ORCID ID oooo-0002-2321-3864 [Makale kayıt tarihi: o8.09.2020-kabul tarihi: 20.11.2020; DOI: 10.29000/rumelide.822037]

Yüksek Lisans Öğrencisi, Ağrı İbrahim Çeçen Üniversitesi, Sosyal Bilimler Enstitüsü, Rus Dili ve Edebiyatı Anabilim Dalı, Rus Dili ve Edebiyatı Bölümü (Ağrı, Türkiye), o1canfatoso1@gmail.com, ORCID ID:0ooo-ooo2-2368-8480 e-posta: editor@rumelide.com 


\title{
On Turkish-Russian, Russian-Turkish text translation courses in the example of Agri İbrahim Cecen University
}

\begin{abstract}
There are many types of translations available today: synchronized, sequential in conferences, radio and television broadcasts (media), cassette recordings, etc. And in this context, the role of a good translator in the modern world will always be at the forefront. Russian-Turkish and TurkishRussian translation studies are growing in connection with the development of cultural, economic and political ties. At the same time, learning the Russian language gives the opportunity to communicate with representatives of the countries of the Commonwealth of Independent States. In teaching the Russian language in a non-linguistic environment (especially in Turkey), important factors must be considered. This is, above all, a matter of mindset for the education system. Increasing the cultural accumulation of students and practical transfer of information about the characteristics of the national education system to students will contribute to the improvement of the educational process. As lecturers of the Faculty of Letters and Sciences of Ağrı İbrahim Çeçen University we observe some of the difficulties faced by Turkish students in all Turkish-Russian and Russian-Turkish translation courses First, it is useful to identify the reasons for overcoming difficulties. Some of these reasons are listed below:. To overcome difficulties, First it is useful to identify the reasons. Below are some of these reasons: It should not be forgotten that one of the most difficult areas is grammar when it is analyzed in terms of teaching "Turkish-Russian" and "Russian-Turkish" translation lessons in the process of teaching Russian Language and Literature to Turkish students. Because most of the words in Turkish are ambiguous, and these words correspond to several meanings in the Russian language, each completely different from each other. In this study, the characteristics of phonology, Turkish-Russian and Russian-Turkish translation, intercultural communication, Russian-Turkish cultural dialogue and teaching of other disciplines in the Department of Russian Language and Literature of the Faculty of Arts and Sciences are emphasized. In the case of Ağrı İbrahim Çeçen University, Turkish-Russian, Russian-Turkish translation lessons, the difficulties observed in the lessons and the solution suggestions constitute the aim of the study.
\end{abstract}

Keywords: Translation, Agrı Ibrahim Çeçen University, Intercultural Communication, characteristics of Turkish and Russian languages, national and cultural characteristics

\section{Giriş}

Ağrı İbrahim Çeçen Üniversitesi'nde Filoloji Fakültesi'nin bölümlerinden biri olan Rus Dili ve Edebiyatı Bölümü 2011 yılında açılmıştır. Söz konusu bölümde, Rus edebiyatı üzerine bilimsel araştırma yapan, Rus dilinin dilbilgisinde, bir dilden diğerine çeviri özelliklerini inceleyen yüksek nitelikli öğretim üyeleri çalışmaktadır. Bölümün ana amacı, Rusçadaki eserleri okuyabilecek ve anlayabilecek uzmanları ve aynı zamanda bilimsel faaliyetlerde bulunabilen, Rus dili alanındaki çalışmalarda en iyi sonuçları elde edebilen araştırmacıları hazırlamaktır. Derslerde öğrenciler telaffuz, algı, okuma ve yazma becerilerini geliştirmektedirler. M. V. Lomonosov, V.A. Jukovski, A. S. Puşkin, M. Y. Lermontov, N. V. Gogol, N.A. Nekrasov, F. M. Dostoyevski, L. N. Tolstoy, A.P. Çehov gibi Rus edebiyatının ünlü şair ve yazarlarının orijinal metinleri analiz yoluyla incelenmektedir. Bölümü bitiren mezunlar, turizm alanlarında tercüman ve ayrıca ortaokul, lise ve kolejlerde Rus Dili ve Edebiyatı öğretmeni olarak çalışabilmektedirler. 
Ağrı İbrahim Çeçen Üniversitesi Fen Edebiyat Fakültesi Rus Dili ve Edebiyatı bölümü aşağıda sıralanan disiplinleri içermektedir:

\section{Sınıf için:}

- Ses bilgisi;

- Kültürlerarası İletişim: Rus-Türk Kültür Diyaloğu;

- Edebiyat Bilimine Giriş I, II.

- Rusça-Türkçe Çeviri I,II.

\section{Sinıf için:}

- Rusça-Türkçe Çağdaş Metin Çevirisi I, II;

- 19. Yy. Rus Edebiyatı I.

\section{Sınıf için:}

- Yazım Kuralları I, II;

- Rusça Türkçe Metin Çevirisi I, II;

- 19. Yy. Rus Edebiyatı II;

- Antik Edebiyat;

- Batı Edebiyatı (18-19.yy);

- 20.yy Rus Edebiyatı I.

\section{Sınıf için:}

- Retorik (İyi Konuşma Sanatı) I, II;

- Stilistik (Üslup Kurallarına Giriş) I, II;

- Edebiyat Teorisi;

- Rusça-Türkçe Edebi Çeviri I, II;

- Türkçe-Rusça Edebi Çeviri I, II;

- 20. yy. Rus Edebiyatı II, III.

\section{Türk ve Rus dillerinin özellikleri}

Rus dili dünyanın en zengin dillerinden bir tanesi olarak kabul edilmektedir. Rus dilinin zenginliği ve temelinde oluşturduğu edebiyat, hem dünyada, hem de Türkiye'de bu dile olan ilgiyi arttırmaktadır.

Rusça ve Türkçe iki ayrı gramer sistemlerine sahip, farklı dil aile grubuna mensup dilleri temsil etmektedir. Rusçada zaman kategorisi şimdiki, gelecek ve geçmiş zaman olmak üzere üç ana zaman dilimine ayrılmaktadır (Bondarko,1971: 50). Türkçe ise, Rus diline göre, daha karmaşık bir zaman sistemine sahiptir3.

3 Türkçe 'de mevcut zaman dilimleri konusunda çeşitli görüşler bulunmaktadır. Kimi araştırmacılar dört temel zaman diliminden bahsederken, kimi bilim adamları ise geçmiş zamanı görülen ve duyulan olmak üzere ikiye ayırarak, Türkçe'de zamanları beş temel zaman diliminde incelemektedir. Türkçe 'de zamanlar konusu, araştırmamız içerisinde ana konuyu teşkil etmediğinden çalışma içerisinde bu konuya ayrıntılı olarak değinilmemiştir. 
Rusçada gelecek zaman diliminin ikincil anlamı olarak ele alınan; Türkçede ise ayrı bir zaman dilimi olarak incelenen geniş zamanın, Türkçeden Rusçaya çevirisi bazı zorluklara ve çeviri alanında farklı gramer şekil ve kalıplarının seçilmesine yol açmaktadır.

\section{III. Çeviri derslerinde Türk öğrencilerin karşılaştıkları zorluklara dair}

Özellikle Türkçe-Rusça çeviri derslerine dikkat çekmek gerekmektedir. Çünkü öğrenciler birincil olarak bu derslerde zorluklar yaşamaktadır.

Söz konusu makalede Rusçayı yabancı bir dil olarak öğrenen Türk öğrencilerin karşılaştıkları en önemli sorunlardan birisi olan Türkçe-Rusça ve Rusça-Türkçe çeviri alanlarında materyaller bulunmaktadır. Türk öğrenciler, kaynak metinden erek metine çeviri yaparken birtakım zorluklar yaşamaktadırlar. Bunlardan bazıları; anlatılmak istenenin doğru bir şekilde çevrilememesi, dil bilgisel olarak doğru sözlüklerin ve öğelerin kullanılamaması ve çevrilmek istenen metnin anlam ve mantık hatası olmadan Türkçeden Rusçaya aktarılamaması olarak sıralanabilir.

III. ve IV. sınıf öğrencileri için Türkçe-Rusça çeviri dersleri üzerine iki adet ders kitabı hazırladık. Ders kitapları Ağrı İbrahim Çeçen Üniversitesi Fen Edebiyat Fakültesinin öğrencileri için tasarlanmış olmakla birlikte, diğer üniversitelerin öğrencileri tarafından da başarıyla kullanılabilecek nitelikler taşımaktadır.

Ders kitabının sözcük bilimsel materyali, öğrencilerin sosyal, ticari, kültürel vb. çeşitli iletişim alanlarında, Türkçe-Rusça ve Rusça-Türkçe çeviri yeteneklerini geliştirmeyi amaçlamaktadır.

Her ders kitabı on iki konudan oluşmakta olup, iki ders dönem için tasarlanmıştır. Her konu, metin öncesi görevler, ana metin, kelime bilgisi, metin sonrası görevler, Türkçe-Rusça, Rusça-Türkçe Sözlük ve farklı alıştırma türleri içermektedir.

Ders kitabında sunulan alıştırmalar, bu konudaki konuşma becerilerinin geliştirilmesine odaklanmıştır. Uygulamaların belli bir bölümü, öğrencilerin bağımsız çalışmalarını geliştirmeyi amaçlamaktadır: metne yönelik soruların derlenmesi, kelimelerin eş ve zıt anlamlarının yazılması ve onlarla cümle oluşturulması, metin planının ve özetinin hazırlanması.

Böylece, öğrencilerin Rus dilini iletişim dili olarak kullanabilme ve yetkin olarak Rusçayı doğru bir şekilde konuşma becerilerinin geliştirilmesi gibi, öğrenmenin temel amaçlarına ulaşılması hedeflenmiştir.

Türkçe-Rusça çeviri derslerinin hazırlanmasında uygulanan yöntem hakkında kısaca bilgi vermek uygun olacaktır.

İlk derslerden başlayarak metin, metinlerden hemen sonra da bir sözlük verilmektedir. Sözlüğün hemen arkasında metinle ilgili sorular bulunmaktadır. Sorulardan sonra aşağıdaki görevler verilir:

1. Aşağıdaki kelimelerin eș anlamlarını karşılarına yazınız ve onlarla cümle oluşturunuz;

2. Aşağıdaki kelimelerin zıt anlamlarını karşılarına yazınız ve onlarla cümle oluşturunuz;

3. Metnin planını Rusça oluşturunuz;

4. Metni Rusça özetleyiniz. 
Her metnin sonunda öğretilenlerle ilgili sorular “ödev” olarak verilmektedir.

Türkçe-Rusça ders kitaplarının özellikleri üzerinde ayrıntılı olarak durmak istiyoruz. Derslerin hazırlanmasında uygulanan yöntem hakkında da bilgi vermek uygun olacaktır.

\section{III.I. Türkçe-Rusça Metin Çevirisi (III. Sınıf).}

Bu kitap, iki dönem için tasarlanmıştır. Her iki dönemde 6 ders olmak üzere toplam 12 ders vardır. Kitabın II. eğitim-öğretim yarıyılı konuları 34 sayfadan oluşmaktadır. Derslerde sözcükler, kelime grupları (terkibi) metnin sonunda verilmiştir. Ders konuları çok çeşitlidir.

II. eğitim-öğretim yarıyılı aşağıdaki metin ve konuları içerir:

1. Oscar Wilde "Mutlu Prens".

2. Aziz Nesin "Şimdiki Çocuklar Harika". Çalışan Kazanır.

3. Hans Christian Andersen "Eski ev" - (1. Bölüm).

4. Hans Christian Andersen "Eski ev" - (2. Bölüm).

5. Hans Christian Andersen "Bezelye Üstündeki Prenses".

6. Jonathan Swift "Gulliver'in Gezileri”.

“Türkçe-Rusça Metin Çevirisi - III. Sınıf” adlı bu kitabın, Rusça öğrenen Türk öğrenciler için faydalı bir kaynak olacağı düşünülmektedir.

\section{II. Türkçe-Rusça Edebî Çeviri I (IV. Sınıf).}

Önceki ders kitabında olduğu gibi bu kitap da iki dönem için tasarlanmıştır. Her iki dönemde 6 ders, toplamda 12 ders vardır. Kitabın I. eğitim-öğretim yarıyılı ders konuları 40, II. eğitim-öğretim yarıyılı ders konuları 36 sayfadan oluşmaktadır. Derslerde sözcükler, kelime grupları (terkibi) metnin sonunda verilmiştir. Ders konuları çok çeşitlidir.

Söz konusu çalışmada öncelikli olarak A. S. Puşkin’in "Yaşamı ve Sanatı", "Yevgeni Onegin” şiirromanı, İ.A. Bunin'in "Mitya'nın Aşkı”, F.M. Dostoyevski ve A.P. Çehov'un "Yaşamı ve Sanatı" gibi çeşitli Türkçe edebî metinlerine yer verilmiştir.

I. eğitim-öğretim yarıyllı aşă̆ıdaki metinleri içerir:

1. Fyodor Mihayloviç Dostoyevski.

2. Aziz Nesin "Şimdiki Çocuklar Harika" (Roman). Birinci Olacaksın.

3. Anton Pavloviç Çehov.

4. Sergey Aleksandroviç Yesenin.

5. Anna Akhmatova ve Kiev.

6. Mihail Aleksandroviç Şolohov.

II. eğitim-öğretim yarıyılı aşağıdaki metinleri içerir:

1. Reşat Nuri Güntekin "Çalıkuşu” - (1. Bölüm).

2. Reşat Nuri Güntekin “Çalıkuşu” - (2. Bölüm). 
3. Reşat Nuri Güntekin “Çalıkuşu” - (3. bölüm).

4. Aleksandr Sergeyeviç Puşkin.

5. A.S. Puşkin "Yevgeni Onegin".

6. İvan Alekseyeviç Bunin “Mitya’nın aşkı” (parça).

\section{IV. Çeviri örnekleri}

Ağrı İbrahim Çeçen Üniversitesi Rus Dili ve Edebiyatı Bölümü öğrencileri tarafından Rusçadan Türkçeye bazı eserlerden yapılmış birkaç çeviri örneği.

\section{Sınıf - IV курс}

\section{Anna Akhmatova'nın anıları}

Özellikle Anna Akhmatova'nın Kiev'i ilk kez beş yaşında ziyaret ettiğine dair bir kayıt bulunmaktadır. Tüm kış boyunca, Gorenko ailesi Ulusal Otel'de yaşadı.

Muhtemelen, bahçede bir sirk veya hayvanat bahçesi vardı, çünkü Anya ve kız kardeşi Rika (İrina) burada korkunç bir macera yaşamıştı: iki kardeş dağdan aşağı koştular ve bir ayı kafesinin içine düştüler. Rastgele yoldan geçen bir kız çocukları kurtardı.

\section{Воспоминания Анны Ахматовой}

В частности, сохранилась запись о том, что Анна Ахматова впервые побывала в Киеве в возрасте пяти лет. Всю зиму семья Горенко жила в гостинице «Националь».

Возможно (наверное), в саду был бродячий цирк или зверинец, потому что Аня и её сестра Рика (Ирина) пережили здесь страшное (ужасное) приключение: две сестры сбежали вниз с горы и упали (попали) в медвежью клетку (в загородку с медведем). Случайная прохожая спасла девочек.

\section{Sinıf - III курс}

\section{Hans Christian Andersen "Eski ev" - (1. Bölüm)}

Çocuk bir Pazar günü, bir kâğıt parçasına bir şeyi sararak hizmetçiye vermiş:

- Bu paketi, karşı evde yalnız yaşayan yaşlı adama verirsen sevinirim. Benim iki kurşun askerim vardı. Adamcağız yalnız kalmasın diye birini ona veriyorum, demiş. Hizmetçi, içinde kurşun askerin bulunduğu paketi alıp eski eve götürmüş. Aradan bir süre geçtikten sonra, yaşlı adamcağız çocuğu evine çağırmış. $\mathrm{O}$ da annesinden izin alıp yaşlı adamın evine gitmiş.

Ганс Христиан Андерсен «Старый дом» - (1-ая часть)

В воскресенье мальчик завернул что-то в лист бумаги и отдал слуге:

- Я был бы рад, если ты передашь этот пакет пожилому человеку, который живёт один в противоположном доме (в доме напротив). У меня было два оловянных солдатика. Мальчик сказал, что дарит пожилому человеку одного из своих солдатиков, чтобы тот не остался один. Слуга взял пакет с оловянным солдатиком и отнёс его к старому дому. Через некоторое время пожилой человек позвал мальчика к себе домой. Мальчик взял разрешение у своей матери и пошёл в дом старика.

\section{Rusça-Türkçe çeviri kitapları}

Ayrıca, 2020'de yayınlanan üç ders kitabı (II. baskı) hakkında birkaç kelime söylemek istiyoruz. Kitapların I. baskısı 2019 yılında yayınlanmıştır. Bunlar: I. Rusça-Türkçe Çağdaş Metin Çevirisi (II. Sınıf); II. Rusça-Türkçe Metin Çevirisi (III. Sınıf) ve III. Rusça-Türkçe Edebî Çeviri (IV. Sınıf). 
Her ders kitabı Rus dilinin daha derin öğrenilmesinde de çok yararlı olabilecek ödev ve alıştırmalar önermektedir. Bunun sonucunda bu kitap, hem kendi başına, hem de bir öğretmen rehberliğinde Rusça öğrenen insanlar tarafından kullanılabilir.

Derslerin hazırlanmasında uygulanan yöntem hakkında kısaca bilgi vermek uygun olacaktır.

Bilindiği gibi yeni bir dil öğrenirken en çok dikkat edilecek konulardan biri de sözcük öğrenimidir.

İlk dersten başlayarak bir metin verilmiştir. Bunlar, öğretilen bilgilerin uygulandığı, size bilginizi ölçme ve Rusça çağdaş bir metin okuma parçalarıdır. Bunların hemen arkasında metinle ilgili sorular bulunmaktadır. Sorulardan sonra aşağıdaki görevler verilir:

1. Kelimelerle ve kelime grupları ile cümleler oluşturun;

2. Türkçe kısa bir metin özeti yazın.

Her metnin sonunda öğretilenlerle ilgili sorular “Ödev” olarak verilmektedir.

Metinlerdeki kelimeler vurgularla (aksanlarla) verilir. Harfler koyu kalın yazı tipiyle vurgulanır. Bu, ders kitabının özelliğidir.

Her ders kitabının özellikleri üzerinde ayrıntılı olarak durmak istiyoruz. Derslerin hazırlanmasında uygulanan yöntem hakkında da bilgi vermek uygun olacaktır.

\section{V.I. Rusça-Türkçe Çağdaş Metin Çevirisi (II. Sınıf)}

Kitap iki eğitim-öğretim yarıyılı için tasarlanmıştır. Her iki dönemde 12 ders olmak üzere toplam 24 ders vardır. Kitap 71 sayfadan oluşmaktadır Derslerde sözcükler, kelime grupları (terkibi) derste işlenecek konunun başında tablo şeklinde verilmiştir. Ders konuları çok çeşitlidir.

I. eğitim-öğretim yarıyllı aşă̆ıdaki konuları içerir:
1. Tanışma
2. Otobiyografi (Özgeçmiş)
3. Bizim Ailemiz
4. Bizim Üniversitemiz
5. Bizim Dairemiz
6. Benim Günüm
7. Benim Arkadaşım
8. Mevsimler (Yllın Mevsimleri)
9. Kütüphane
10. Benim Hobim
11. Ağrı Benim Memleketim
12. Yeni Yıl (Yılbaşı)

II. eğitim-öğretim yarıyılı aşağıdaki konuları içerir:

1. Kış Tatili 

2. Sevdiğim Hayvanlar
3. Kitaplar Bizim Arkadaşlarımızdır
4. Bilgisayarın Hayatımdaki Rolü
5. Kültürlü İnsan
6. Türk Halkının Gelenek ve Görenekleri
7. Türk Mutfağı
8-9. Türkiye'nin Bayramları
10. Dünya Müzeleri
11. Meyve ve Sebzelerin Faydaları
12. Telefon Görüşmesi Etiketleri

Metinler özel ve emin bir yöntemle derlenmiş olup, metinlerdeki tüm kelimelerin vurguları belirtilmiştir. Bu nedenle kelimelerin okunuşları çok kolaydır.

İlk derslerden itibaren, öğrenciler Rusçadan Türkçeye ve Türkçeden Rusçaya Çeviri yaparken karşılaştığı bazı zorlukları gözlemlemekteyiz. Her şeyden önce, dikkat ettiğimiz şey, Rusça-Türkçe çeviri derslerinde, tüm I-IV Sinıflarda, her zaman sadece çeviri yöntemi kullanılmıştır. Çeviri materyalleri üzerindeki çalışmalar gözle görülür biçimde değiştirilmiştir.

Rusça-Türkçe Çağdaş Metin Çevirisi (II. Sınıf) derslerinde aşağıdaki değişiklikler yapılmıştır:

1) metni Türkçeye çevirin;

2) soruları cevaplayın (önce Rusça, daha sonra Türkçe);

3) verilen kelimelerle cümleler oluş̧urun (kelimeler metinden verilir);

4) Türkçe metnin kısa özetini yazın.

II. Sınıf Öğrencileri için hazırlanmış bu ders kitabında özellikle çağdaş metinlere yer verilmiş, çeviri yapılırken iki dil arasında kültürel ve sosyal bağlar kurulması amaçlanmıştır.

\section{V.II. Rusça Türkçe Metin Çevirisi (III. Sınıf).}

Aynı bu kitap da iki dönem için tasarlanmıştır. Her iki eğitim-öğretim yarıyılında 12, toplamda 24 ders vardır. Kitap 93 sayfadan oluşmaktadır Derslerde sözcükler, kelime grupları (terkibi) metnin sonunda verilmiştir. Ders konuları çok çeşitlidir.

I. eğitim-öğretim yarıyılı aşağıdaki metin ve konuları içerir:

1. Rus Dilinin Yaşamımızdaki Rolü ve Önemi

2. Rusya'nın Şair ve Yazarları

3. Büyük Rus Yazarı Lev Nikolayeviç Tolstoy

4. Turizm Nedir?

5. Turizm Çeşitleri (Su, Dağ, Sağlık, Kayak)

6. Turizm Çeşitleri (Deniz, Etnik, Hac, Macera, Eğlence)

7. Turizmin Gelişiminde Reklamın Rolü

8. Yabancı Dillerin Hayatımızdaki Rolü 

9. Yeni Yılı Nasıl Kutladım?
10. Öğrencinin Arkadaşına Mektubu
11. O. Henry "Son Yaprak"
12. Anne ve Futbol

II. eğitim-öğretim yarıyılı aşağıdaki metin ve konuları içerir:
1. K.G. Paustovski "Hırsız Kedi”
2. Lev Kassil "Sevgili Çocuklarım"
3. Dünyanın En Güzel Şehirleri
4. Ankara: Türkiye'nin Başkenti
5. Spor
6. Olimpiyat Oyunları
7. Ekstremal Turizm
8. Köy Turizmi
9. Plaj Turizmi
10. Dünyanın Harikaları
11. Dünyanın Yedi Harikası
12. İ. Levçenko "Hızlı Trende"

Rusça-Türkçe Metin Çevirisi (III. Sınıf) çalışmamızda hissedilir ölçüde değişiklikler yapılmıştır:
1) Metni Türkçeye çevirin;
2) Soruları cevaplayın (önce Rusça, daha sonra Türkçe);
3) Metnin planını oluşturun;
4) Türkçe metnin kısa özetini yazın.

“Rusça-Türkçe Metin Çevirisi - III. Sınıf” adlı bu kitabın, Rusça öğrenen Türk öğrenciler için faydalı bir kaynak olacağı düşünülmektedir.

\section{V.III. Rusça-Türkçe Edebî Çeviri (IV. Sınıf)}

Önceki ders kitaplarında olduğu gibi iki eğitim-öğretim yarıyılı için tasarlanmıştır. Her iki dönemde de 12 ders olmak üzere, toplam 24 ders vardır. Kitap 115 sayfadan oluşmaktadır. Derslerde sözcükler, kelime grupları (terkibi) metnin sonunda verilmiştir. Ders konuları çok çeşitlidir.

Çalışmada öncelikli olarak L.N. Tolstoy'un "Savaş ve Barış", B. A. Şatilov "Puşkin Lisede”, İ.A. Bunin "San Fransisko Beyefendisi”, J. London "Hayat Aşkı", A.N. Ostrovski "Fırtına" gibi çeşitli Rusça edebî metinlerine yer verilmiştir.

I. eğitim-öğretim yarıyılı aşağıdaki metinleri içerir:

1. K. G. Paustovski "Porsuk Burnu”

2. Yeryüzündeki En Soğuk Yer (Şehir)

3. St. Petersburg

4. L.N. Tolstoy "Savaş ve Barış" (Meşeyle/Meşe Ağacıyla Karşlaşma)

\footnotetext{
Adres | Address 
5. V.G. Mezentsev “Kar”

6. V. M. Peskov "Kimse Timsahları Sevmez"

7. L.N. Tolstoy “Köpekbalığı”

8. D. S. Lihaçev "İnsan Aydın Olmalıdır”

9. B. A. Şatilov "Puşkin Lisede"

10. "Hayatın Anlamı Nedir?” (Mesel/Destan)

11. İnsanlar Isıyı Hissedebilirler mi?

12. V. G. Rasputin "Fransızca Dersleri”

II. eğitim-öğretim yarıyılı aşă̆ıdaki metinleri içerir:

1. K. G. Paustovski “Telgraf”

2. A.P. Çehov "Kaştanka"

3. A. İ. Kuprin "Fil"

4. İ.A. Bunin "San Fransisko Beyefendisi"

5. M. Gorkiy "Çocukluğum"

6. J. London "Hayat Aşkı"

7. İ. S. Turgenev "Mumu"

8. J. London "Beyaz Diş"

9. O. Henry "Kızılderililerin Reisi"

10. L.N. Tolstoy "Balodan Sonra"

11. M.Y. Lermontov "Mtsiri” (Acemi)

12. A.N. Ostrovski "Firtına"

Rusça-Türkçe Edebi Çeviri derslerinde aşağıdaki değişiklikler yapılmıştır:

1) Metni Türkçeye çevirin;

2) Metinle ilgili sorular hazırlayın/oluşturun (önce Rusça, daha sonra Türkçe);

3) metnin planını oluşturun;

4) Türkçe metnin kısa özetini yazın.

Tabii olarak, ders içeriklerine böyle bir yaklaşım ilk başta öğrenciler üzerinde bir şok etkisi yaratmıştı, çünkü onlar metinlerin monoton, sıkıcı çevirisine alışmışlardı. Ancak zamanla bu engelin de üstesinden geldik.

Öğrencilerimiz tarafından Rusçadan Türkçeye birkaç eserden yapılmış çeviri örneği.

\section{Sinıf - II кypc}

\section{Турецкая кухня}

ТурЕцкая кУхня - однА из сАмых дрЕвних, богАтых и вкУсных в мИре.

ТурЕцкий зАвтрак... НастоЯщий турЕцкий зАвтрак поИстине мОжно назвАть королЕвским, потомУ что он бОльше напоминАет швЕдский стол. Здесь есть свЕжие помидОры, огурцЫ, пЕрец и зЕлень, мАсло, сыр, олИвки, мёд, Яйца, колбАсы и жАреные сосИски, варЕнъе, хлеб. 
On Turkish-Russian, Russian-Turkish text translation courses in the example of Agri İbrahim Cecen University / K. T. Karimova, C. İnal (pp. 860-871)

\section{Türk mutfağı}

Türk mutfağı - dünyanın en eski, en zengin, en lezzetli mutfağından biridir.

Türk kahvaltssı... Gerçek bir Türk kahvaltısı gerçekten Kraliyet olarak adlandırlabilir, çünkü daha çok açık büfeyi hattrlatıyor. Burada taze domates, salatalık, biber ve yeşillik, tereyağı, peynir, zeytin, bal, yumurta, sucuk ve kızarmış sosis, reçel, ekmek var.

\section{Sinıf - III курс}

\section{Спорт}

Лю, ди во всём ми ре лю'бят спорт. Спорт де́ лает их здоро'выми, де́ ржит в хоро шей фо рме, де́ лает бо' лее организо ванными и дисциплини рованными.

Он объединя' ет люде́ й ра' зных сосло' вий и национа' льностей. Мно́ гие лю́ ди занима' ются спо ртом по ли' чной инициати ве. Они' увлека' ются ходьбо й на лы' жах, ката' нием на конька' х, насто льным те' ннисом, пла' ванием, волейбо' лом, бодиби' лдингом и други' ми ви' дами спо' рта.

\section{Spor}

Tüm dünyada insanlar sporu seviyor. Spor onları sağlıklı yapıyor, iyi durumda (formda) tutuyor, fazlasıyla örgütlü, disiplinli yapıyor.

O farklı sınıf ve milliyetlerden insanları birleștiriyor. İnsanların birçoğu kișisel girișimlerde sporla meşgul oluyorlar. Onlar kayak yürüyüşüne, paten yapmaya (sürmeye), masa tenisi, yüzme, voleybol, vücut gelişstirme ve diğer spor türlerine merak sarmaktadırlar.

\section{Sinıf - IV курс}

\section{К. Г. Паустовский «Телеграмма»}

Настя, еди' нственная дочь Катери' ны Петро' вны, жила' далеко', в Ленингра' де. После' дний раз она' приезжа' ла к ма' тери три го да наза' д. Мать зна' ла, что На' сте тепе рь не до неё, стару'хи. У них, у молоды х, свои' дела', свои' интере' сы, своё сча' стье. Поэ 'тому Катери на Петро, вна о чень ре дко писа ла до чери, но ду мала о ней все дни. Пи' сем от Насти то' же не было. Раз в два-три ме' сяца почтальо н приноси' л Катери' не Петро' вне от до чери перево д на две сти рубле' й. На почто вом перево де всегда' бы' ло не 'кколько слов: мно' го дел, нет вре' мени. И Катери' на Петро вна реши' ла сама' написа' ть до' чери письмо' .

\section{K.G. Paustovski "Telgraf"}

Nastya Katerina Petrovna'nın tek kızıydı. Uzakta, Leningrad'da yaşıyordu. Annesinin yanına en son üç yıl önce gelmişti. Anne, Nastya'nın artık ona, bir ihtiyara bağlı olmadığını biliyordu. Onların, gençlerin kendi işleri, kendi ilgileri, kendi mutluluğu vardı. Bu nedenle Katerina Petrovna kızına nadiren mektup yazıyor ama tüm günler (her gün) onu düşünüyordu. Nastya'dan da mektuplar gelmiyordu. İki-üç ayda bir postacı Katerina Petrovna 'ya kizından ikiyiz rublelik para havalesi getiriyordu. Posta havalesinde her zaman birkaç kelime olurdu: Çok iş var, zaman yok. Ve Katerina Petrovna kızına kendisi mektup yazmaya karar verdi.

Çeviri derslerimizde öğrenciler sadece Rus dilini değil, aynı zamanda Rus edebiyatını da öğrenmektedirler. Genellikle sanat eserlerinden çeviriler kullanıyoruz. Bu, öğrencilerin büyük şairlerin ve yazarların yaratıcılığını daha derinden tanımaları için onlara bir firsat sunmaktadır.

Herkes, Rusçayı yabancı dil olarak öğrenme sürecinde, ders kitaplarının çok önemli bir rol oynadığını bilmektedir. Çalıştığımız Rus dili ve Edebiyatı bölümünde çeşitli kitaplar kullanılmaktadır. Bunların arasinda:

Y.Çialaşvili-Gordeyeva "Edebiyat Teorisine Giriş";

L.V. Moskovkin, L.V. Silvina “ Rus Dili” (yabancı öğrenciler için ders kitabı);

I.P. Lısakova ve diğerleri “Rus Dilinin Pratik Üslupbilimi”; 
S. Ramazanova, Y. Çialaşvili-Gordeyeva "Çağdaş Rus dili (Rus Dili ve Edebiyatı okuyan Türk öğrenciler için yardımcı ders kitabı);

B. Demir, S. Aiupova “Rusça Sözlü Anlatım Kitabı”;

Ş. Ramazanova, N. Kipiani "Kültürlerarası İletişim: Rus-Türk Kültür Diyaloğu;

J. Sikuralidze “Deyimler” ve diğerleri.

Türkiye'deki diğer üniversitelerde olduğu gibi, üniversitemizin Rus dili ve Edebiyatı bölümünde, öğretmenler, uzmanlar - eğitim sürecinde yer alan herkes, öğrencilere Rus kültürünü, Rus tarihini, dilbilgisini, edebiyatını en üst düzeyde öğretmeye çalışmaktadır. Türk öğrenciler arasında Rusça dil becerilerini geliştirmek için bölüm uzmanları çeşitli yöntemler, kitaplar, ders kitapları ve öğretim materyalleri kullanmaktadırlar.

"Şu anda, Rus dilini öğrenme sürecinde teknolojik araçların ve malzemelerin kullanımı, Rus dilini öğrenme sürecini hızlandırmayı olanak sağlar. Öğretimde yeni metodların kullanılması, eğitim koşullarının genel olarak iyileştirilmesi, Türk gençliği arasında Rus dili ve Edebiyatına olan ilginin artmasına katkıda bulunmaktadır".4

\section{Sonuç}

Bu çalışma sonunda Ağrı İbrahim Çeçen Üniversitesi örneğinde Türkçe-Rusça ve Rusça-Türkçe metin çevirileri derslerinde karşılaşılan sorunlara değinilmiştir. Özellikle Türkçe ve Rusçanın farklı kültürlere ve dilsel özelliklere ait olmasının, metinlerin çevrilmesinde zorlukların yaşanmasına neden olduğu kanısındayız. Türkçe-Rusça ve Rusça-Türkçe metin çevirilerinde ortaya çıkan sorunlar toplanmış ve bu sorunların çözüm yolları aranmıştır. Bu da çevirmenin çeviri yaptığı dilin kültürü, grameri gibi özelliklerini derinlemesine bilmesinin ne kadar önem taşıdığını göstermektedir.

Sonuç olarak, herhangi bir konunun öğretilmesinde bazı zorluklar olduğunu belirtmek isteriz. Bir öğretmenin görevi, bu zorlukların ortaya çlkış nedenlerini belirlemek, bunların üstesinden gelmenin yollarını ve yöntemlerini bulmaktır.

\section{Kaynakça}

Bondarko A.V. (1971) Vid i vremya russkogo glagola (znaçeniye i upotrebleniye), Prosveşeniye: Moskva. 239 S.

Sonnur A. (2015) Türkiye'de Rus dilini öğretme tarihi (Anadolu Üniversitesi örneğinde). Samara bilim dergisi. № 1 (10), 181 S.

4 Sonnur A. (2015) Türkiye'de Rus dilinin öğretme tarihi (Anadolu Üniversitesi örneğinde). S. 128-130. 